\title{
Performance of Steel I-Beams Strengthened by Fastening Hybrid FRP Strips
}

\author{
Omnia AbouEl-Hamd', Amr Sweedan', Bilal El-Ariss ${ }^{1}$ \\ ${ }^{1}$ United Arab Emirates University \\ P.O. Box 15551, Al-Ain, UAE \\ 200834604@uaeu.ac.ae; Amr.Sweedan@uaeu.ac.ae; Bilal.Elariss@uaeu.ac.ae
}

\begin{abstract}
Fiber-Reinforced Polymers (FRPs) have been widely used in strengthening steel structures. Few researches were conducted to verify the adequacy of strengthening steel structures by fastening FRPs. The current paper reports on the outcomes of an experimental study aimed at strengthening steel I-beams by fastening hybrid FRP (HFRP) strips. A total of ten UB203x102x23 beams were tested in a four-point loading setup. Steel bolts were used to fasten the HFRP strips to the beam bottom flange. The effect of HFRP length was assessed by considering three scenarios $(1,620,1,170$ and $810 \mathrm{~mm})$ that correspond to $90 \%, 65 \%$ and $45 \%$ of the clear span length of tested beams. Single and double HFRP strips were utilized to evaluate the effect of HFRP thickness on the performance of the strengthened beams. Staggered and uniform bolt arrangements were used to assess the effect of bolt arrangement on the performance of the fastened systems. All strengthened beams exhibited better yield and ultimate strength as compared to the control beam. Fastening two HFRP strips with lengths of $90 \%$ of the beam clear span revealed $21 \%$ enhancement in the ultimate capacity of the strengthened beam.
\end{abstract}

Keywords: Hybrid fiber-reinforced polymers (HFRP), strengthened beams, HFRP length, HFRP thickness, bolt arrangement, four-point loading.

\section{Introduction}

Strengthening of steel structures has gained significant importance due to the increasing number of deteriorated steel structures around the globe. The conventional methods of strengthening existing steel structures are typically time consuming, require malfunctioning of the structure and impose extra loads on the existing elements. Recent strengthening practices involve the use of fiber-reinforced polymers (FRP) which offer favorable characteristics including high corrosion resistivity, lightweight and high strength-to-weight ratio. A common technique of upgrading the performance of steel structures involves bonding FRP composites to targeted steel members. Several researchers investigated the effect of the bond: length, shear strength and stiffness on the performance, tensile strength and ductility of bonded FRP-steel joints [1-3]. Earlier researches classified six different failure modes for bonded FRP-steel systems: failure at the steel-adhesive interface, failure at the FRP-adhesive interface, adhesive layer failure, FRP delamination, FRP rupture and steel yielding [4-5]. The behavior of steel beams externally reinforced by bonded FRP laminates was examined thoroughly during the last two decades [6-10]. In 2007 design guidelines for strengthening steel beams using bonded FRP composites were proposed considering the different failure modes of bonded FRP-steel system along with the instructions for surface preparation [11].

Despite the proved efficiency of the bonded technique in enhancing the performance of strengthened steel elements, several drawbacks are associated with its application including: the need for careful surface preparation prior to applying the adhesive and the need for proper curing before implementing the loads. Durability concerns should also be considered while adopting the bonded technique [12]. The brittle nature of the de-bonding failure provoked researchers to use the fastened techniques to strengthen steel elements. Recent studies have been directed to investigate the performance of fastened FRPsteel system [13-17]. The conducted investigations proved the efficiency of the fastening technique in strengthening steel beams. Sweedan et.al [15] reported up to $30 \%$ and $9 \%$ enhancements in the ultimate and yield loads, respectively, for beams strengthened by fastening FRP laminates at their bottom flanges. The previous researches studied the behavior of the strengthened beams under a narrow range of fastening parameters. The current study aims at examining the effect of three main fastening parameters on the performance of steel beams subjected to four-point loading scheme. The considered parameters are: HFRP length, HFRP thickness and bolt arrangement. 


\section{Experimental Program}

The experimental work was conducted utilizing compact UB203x102x23 universal steel beams to examine the effect of HFRP length, HFRP thickness and bolt arrangement on the performance of steel beams strengthened by fastened HFRP strips.

\subsection{Material}

All fabricated beams had an overall length of $2,000 \mathrm{~mm}$ and clear span of $1,800 \mathrm{~mm}$ with $12 \mathrm{~mm}$ thick steel stiffeners. The stiffeners were welded below the loading points, at mid-span and at the supports in order to avoid premature local instability during testing. Two end plates, $12 \mathrm{~mm}$ thick each, were attached to the beam ends. The dimensions of the steel section are shown in Fig. 1, meanwhile the mechanical properties of the beams were obtained by testing six steel coupons per ASTM-A370-18 requirements. Two steel coupons were cut from the web while the other four were cut from the flanges (two from each flange) (see Fig. 2). The lowest reported values were used, revealing yield and ultimate strengths of $405 \mathrm{MPa}$ and $540 \mathrm{MPa}$, respectively and $180 \mathrm{GPa}$ Young's modulus.

Hybrid glass-carbon FRP (HFRP) strips developed by the U.S. Army Engineer Research and Development Center (ERDC) were utilized in the study as they provide a drillable material with adequate strength and ductility. Table 1 shows the dimensional and mechanical properties of the HFRP strips. It is worth noting that the glass and carbon fibers were bonded by highly corrosion resistant resin and covered by a synthetic surfacing veil in order to prevent corrosion at the interface between the HFRP and the steel surface.

Hexagonal galvanized zinc coated M6x40 steel bolts were used to fasten the HFRP strips to the bottom flanges of the steel beams. Bolts were made of high tensile steel of grade 8.8 with diameter of $6 \mathrm{~mm}$, shank length of $40 \mathrm{~mm}$, shear strength of $375 \mathrm{MPa}$ and bearing strength of 1,000 MPa. Flat washers with inner/outer diameters of $8.4 / 28 \mathrm{~mm}$ were used along with $5 \mathrm{~mm}$ thick hexagonal steel nuts to firmly connect the fastened components.

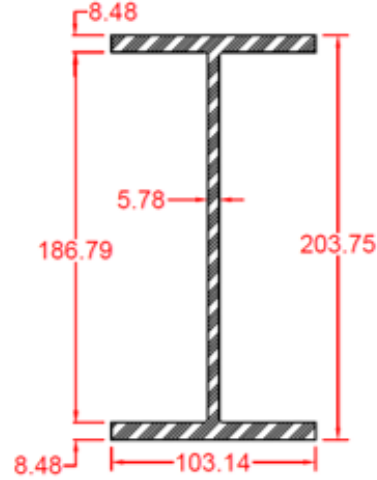

Fig. 1: Typical dimensions of UB203×102x23 cross-section (in $\mathrm{mm}$ ).

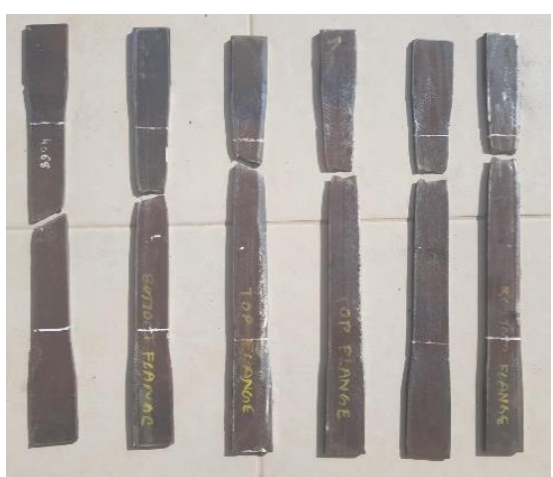

Fig. 2: Tested steel coupons.

Table 1: Dimensional and mechanical properties of the HFRP strips.

\begin{tabular}{|c|c|c|c|}
\hline \multicolumn{2}{|c|}{ Dimensions of the HFRP Strips (mm) } & \multicolumn{2}{c|}{ Mechanical Properties of the HFRP Strips (MPa) } \\
\hline Width & Thickness & Tensile Strength & Elastic Modulus \\
\hline 101.6 & 3.175 & 852 & 62,190 \\
\hline
\end{tabular}

\subsection{Test Matrix}

The experimental program was designed to investigate the effect of three fastening parameters (HFRP length, HFRP thickness and bolt arrangement) on the performance of steel beams strengthened by fastened HFRP strips. Three alternatives of HFRP strip length $(1,620,1,170$ and $810 \mathrm{~mm}$ ) that represent $90 \%, 65 \%$ and $45 \%$ of the beam clear span were considered. For each length, single and double HFRP strips were tested to investigate the effect of HFRP thickness on the strengthened system. The influence of bolts arrangement was tested for beams strengthened with single strip HFRP. It is worth noting that in all tested beams a bolt-spacing of $100 \mathrm{~mm}$ was adopted as recommended by previous 
research [14]. A total of ten beams were tested including one un-strengthened control beam "CB" to provide the reference performance of the steel beams prior to strengthening. The remaining nine specimens were strengthened by fastening HFRP strips to the bottom flange using steel bolts. The designation of each specimen is denoted by three main components. The first component refers to the bolt arrangement: "U" for uniform and "ST" for staggered arrangement. The next number represents the length of the HFRP strip as a percentage of the clear span of the beam: $90 \%, 65 \%$ and $45 \%$. The last component indicates the number of HFRP strips: "1L" for one strip and "2L" for two strips. Table 2 shows a description of the test matrix. Ideally, ensuring accuracy of experimental results could be attained by testing replicates of each sample under same conditions, however, this was not feasible in the current study due to budget constraints. Meanwhile, several measures were considered to maintain the highest accuracy possible including careful design of the experiment and the use of high accuracy instruments that were located properly to capture representative response of the specimens.

Table 2: Description of the test matrix.

\begin{tabular}{|c|c|c|c|c|}
\hline Beam Designation & $\begin{array}{c}\text { Bolt } \\
\text { Arrangement }\end{array}$ & $\begin{array}{c}\text { HFRP Length } \\
(\mathrm{mm})\end{array}$ & $\begin{array}{c}\text { Number of } \\
\text { strips }\end{array}$ & $\begin{array}{c}\text { Total HFRP } \\
\text { Thickness (mm) }\end{array}$ \\
\hline CB & None & 0 & 0 & 0 \\
\hline U-90-1L & Uniform & 1,620 & 1 & 3.175 \\
\hline U-65-1L & Uniform & 1,170 & 1 & 3.175 \\
\hline U-45-1L & Uniform & 810 & 1 & 3.175 \\
\hline U-90-2L & Uniform & 1,620 & 2 & 6.350 \\
\hline U-65-2L & Uniform & 1,170 & 2 & 6.350 \\
\hline U-45-2L & Uniform & 810 & 2 & 6.350 \\
\hline ST-90-1L & Staggered & 1,620 & 1 & 3.175 \\
\hline ST-65-1L & Staggered & 1,170 & 1 & 3.175 \\
\hline ST-45-1L & Staggered & 810 & 1 & 3.175 \\
\hline
\end{tabular}

\subsection{Specimen Preparation}

One of the main advantages of adopting the fastening technique in strengthening steel beams is eliminating the extensive surface preparation processes required prior to applying the bond in the bonded technique. The preparation procedures of the fastened HFRP-steel system are simple and require basic labor skills. Sandpaper and paint remover were used to remove the paint and smoothen the steel surface at the specified locations of the strain gauges. A minimum sheared edge distance of 50 mm was maintained in all HFRP strips as recommended in Ref. [14]. The M6 steel bolts were then used to attach the HFRP strips to the bottom flange of the steel beams. Two washers per bolt were utilized to increase the bearing area at both sides of the connection. Bolts were fastened using a breaking torque wrench by applying $11 \mathrm{~N} . \mathrm{m}$ torque that represents the snugtight condition. Locations of the strain gauges were carefully marked on both the HFRP strips and the steel beams. Electrical resistance strain gauges were mounted at the specified locations to allow for capturing the strain distribution along the HFRP strips and across the beams' cross-sections.

\subsection{Test Setup}

The implemented four-point loading scheme enabled for investigating the behavior of the beams under pure flexure along the middle segment. Tests were conducted in a displacement-controlled manner with a rate of $1.5 \mathrm{~mm} / \mathrm{min}$ to allow for capturing the post-peak response of the beams. Load was applied using $500 \mathrm{kN}$ MTS hydraulic jack that was fixed to a strong resisting frame. As the tested beams were seated on slightly short roller-supports, a steel loading-column was designed and firmly fixed to the hydraulic jack in order to transfer the expansion of the stroke to the other components of the set-up. A $500 \mathrm{kN}$ load-cell was placed below the loading-column to accurately record the applied loads. A $900 \mathrm{~mm}$ long built-up spreader beam was used to transfer the load to the tested beams. The bottom flange of the spreader beam was welded to two rollers spaced $300 \mathrm{~mm}$ from the center of the beam, resulting in a spacing of $600 \mathrm{~mm}$ between the two loading points. Figure 3 shows schematic and realistic views of the test set-up. 

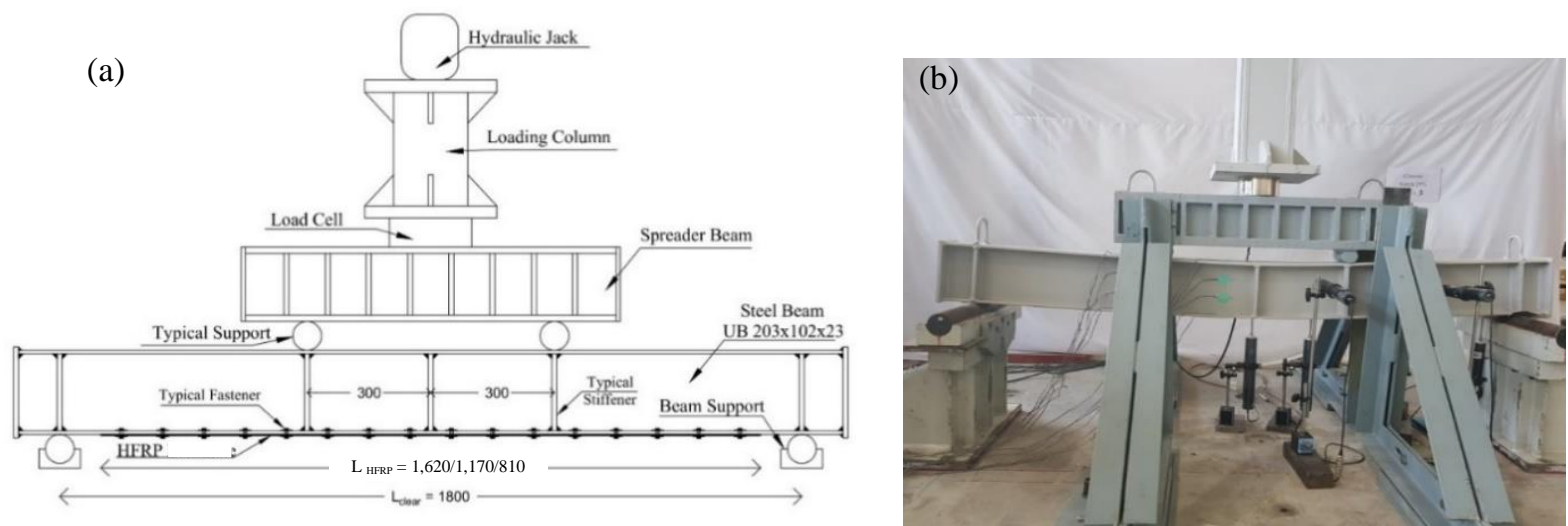

Fig. 3: (a) Schematic of the test setup (Dimensions in "mm") (b) Photo of the test set-up.

Four LVDTs were positioned along the span of the beam to measure the vertical displacements and to acquire the deflection profile of the tested beams. Two more horizontal LVDTs were placed perpendicular to the web of the beam to measure any out-of-plane deflection in case of lateral torsional buckling (Fig. 4). It is worth mentioning that the midspan LVDT was used to generate the load-deflection curve of each beam. Five strain gauges were mounted at the crosssection of the beam at the mid-span region to obtain the strain profile at the pure moment zone (SG1 to SG5). Another five strain gauges (SG6 to SG10) were placed over the beams cross-section in the combined shear-moment zone. More strain gauges were positioned along the HFRP strip to enable monitoring the strain distribution over the strip length. Figure 4 shows a sample instrumentation for a steel beam strengthened by 1,620 mm long HFRP strip utilizing uniform bolts.

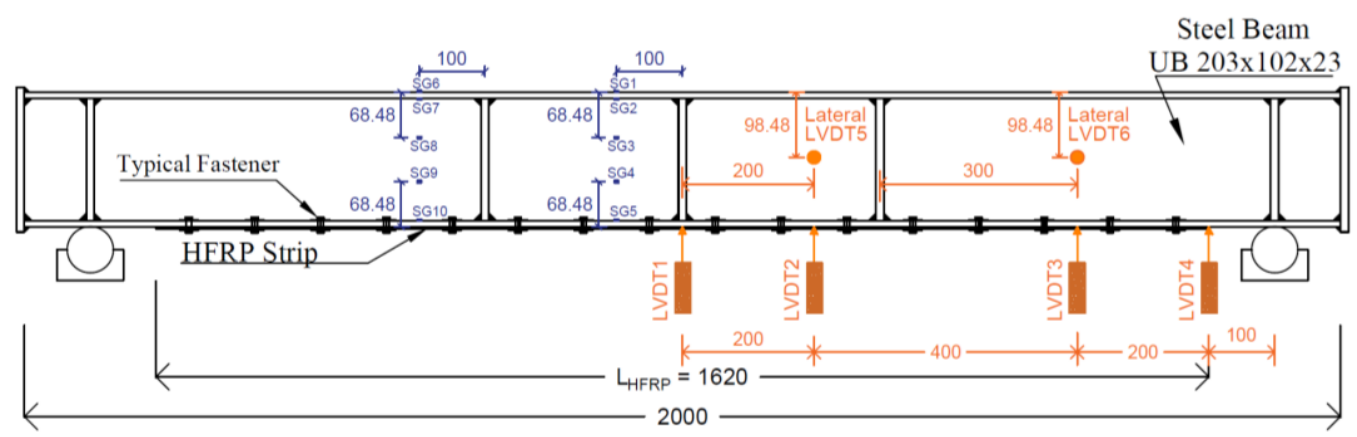

Fig. 4: Typical specimen instrumentation (Dimensions in “mm”).

\section{Results and Discussions}

The experimental response of all tested specimens is displayed in view of the load-deflection relations. All beams were loaded up to a minimum mid-span deflection of $55 \mathrm{~mm}$ in order to capture the post-peak response of the tested specimens. Discussions of the obtained results are outlined in the following subsections.

\subsection{Effect of HFRP Length}

Load-deflection curves for beams strengthened by a single HFRP strip with different lengths of $90 \%, 65 \%$ and $45 \%$ of the span length using uniform bolt arrangement are displayed in Fig. 5 (a). Plotted deflections correspond to the measurements of LVDT 1 at the mid-span. A typical load-deflection curve for a control beam was composed of three main regions as shown in Fig. 5. The elastic behavior of the beam continued until a load value of about $260 \mathrm{kN}$, at which full yielding of the mid segment section takes place. After that, the beam underwent plastic deformations, where the additional loads caused considerably high deflections attaining a peak load of $352 \mathrm{kN}$ at deflection of $44 \mathrm{~mm}$. Then, a gradual reduction in the load was observed as a result of the top flange buckling and beam torsion. Figure 5 (a) shows the enhanced performance of the strengthened beams compared to the control beam. Increasing the length of a single HFRP strip from $45 \%$ to $90 \%$ of the span length resulted in enhancements of $6.41 \%$ and $13.13 \%$ in the yield and ultimate loads as compared to the control beam, respectively. Meanwhile, the effect of HFRP length became apparent with 
doubling the thickness of the HFRP strips. Figure 5(b) presents the load-deflection plots for beams strengthened by fastening two HFRP strips using uniform bolt arrangement. Using HFRP strips with lengths that are 45\%, 65\% and $90 \%$ of the span length showed yield load enhancements by $9.62 \%, 9.62 \%$ and $15.38 \%$ respectively. Moreover, the ultimate load of the control beam was enhanced by $11.93 \%, 15.44 \%$ and $21 \%$ for the three constitutive lengths. The effect of HFRP length can also be observed by comparing the performance of the beams strengthened utilizing staggered bolt arrangements, as shown in Fig. 5 (c). Fastening a single HFRP strip with lengths that are $45 \%, 65 \%$ and $90 \%$ of the span length using steel bolts in staggered arrangement, boosted the ultimate capacity of the beams by $8.34 \%, 11.54 \%$ and $15.09 \%$, respectively. One can conclude that the effect of HFRP length became apparent with the use of thick HFRP strips and staggered bolts. Enlarging the HFRP length enhanced both the yield and ultimate loads of the strengthened beams.
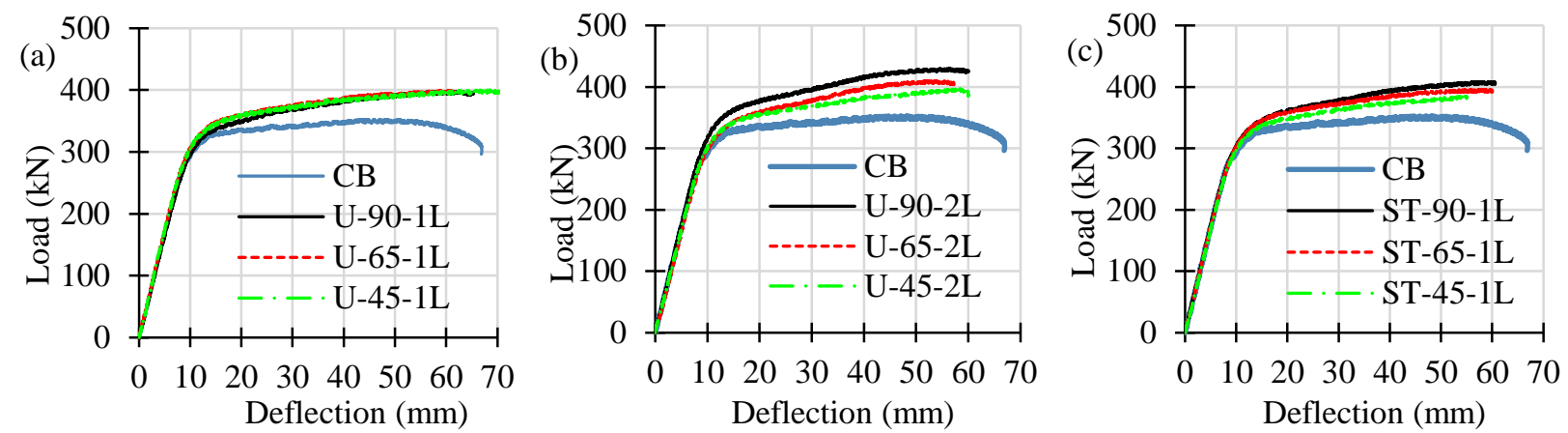

Fig. 5: Load-deflection curves for the effect of HFRP length: (a) uniform bolts with single HFRP strip, (b) uniform bolts with two HFRP strips and (c) staggered bolts with single HFRP strip.

\subsection{Effect of HFRP Thickness}

The effect of HFRP thickness on the performance of the strengthened steel beams was investigated utilizing single $(3.175 \mathrm{~mm})$ and double $(6.35 \mathrm{~mm})$ HFRP strips. The load-deflection plots for the beams strengthened by HFRP strips that are $90 \%, 65 \%$ and $45 \%$ of the span length, utilizing single and double HFRP strips are presented in Figs. 6 (a, b and c). The effect of HFRP thickness on the strengthened beams became more apparent with the use of long HFRP strips. Doubling the thickness of the HFRP strip that was $90 \%$ of the span length caused yield and ultimate load improvements by $15.38 \%$ and $21 \%$, respectively, relative to the control specimen. It is worth noting that the failure of those beams was governed by local buckling of the top flange, as shown in Fig. 7. Figure 8 presents the deflection profile of U-90-1L and U-90-2L along with the deflection of the control beam at load of $290 \mathrm{kN}$. The beam deflection was significantly reduced by fastening the two HFRP strips to the beam bottom flange. Meanwhile, doubling the thickness of the HFRP strips that were $65 \%$ of the span length revealed similar load-deflection trend up to displacement of $30 \mathrm{~mm}$, after which $2.63 \%$ improvement in the ultimate load was observed. Utilizing two strips of the short HFRP strips (with length of $45 \%$ of the span length) had insignificant effect on the yield load, ultimate load and load-deflection curve. The response of this configuration was controlled by shear failure of the end bolts at displacement of $40 \mathrm{~mm}$ as shown in Fig. 9. The stress redistribution after the fracture of the end bolts caused progressive failure of the fasteners revealing negligible contribution of the fastened HFRP strip in enhancing the performance of the steel beam. 

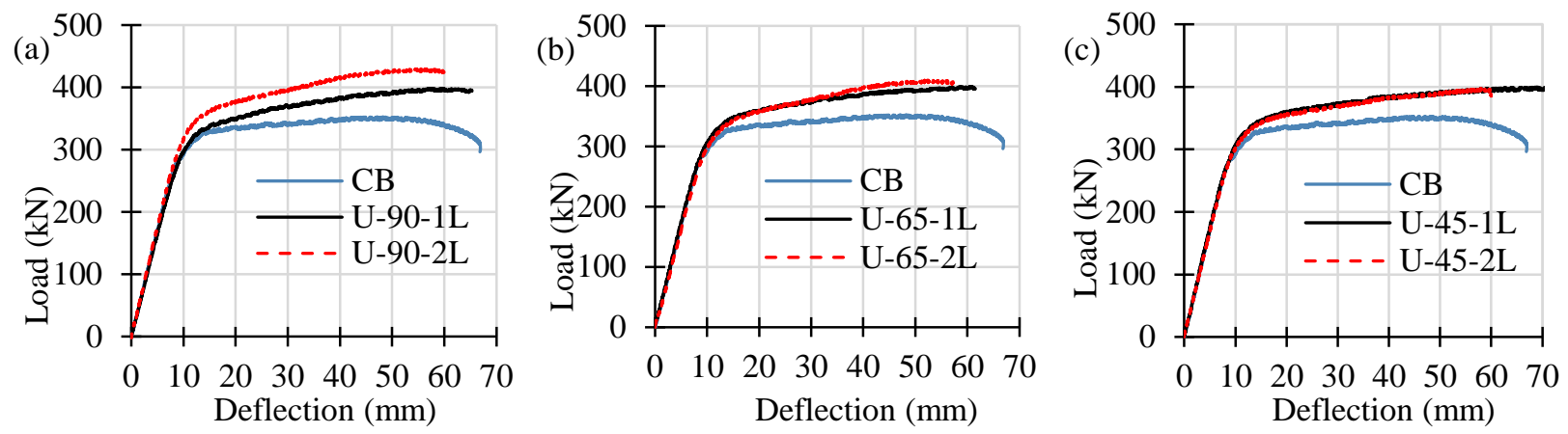

Fig. 6: Load-deflection curves for the effect of HFRP thickness utilizing uniform bolts with different HFRP lengths: (a) $90 \%$ of the span length, (b) $65 \%$ of the span length and (c) $45 \%$ of the span length.

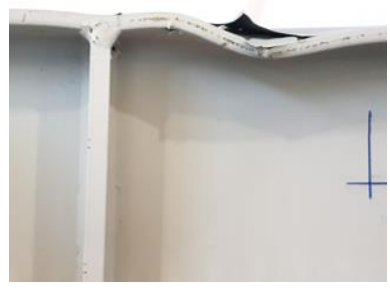

Fig. 7: Top flange buckling of U-90-2L

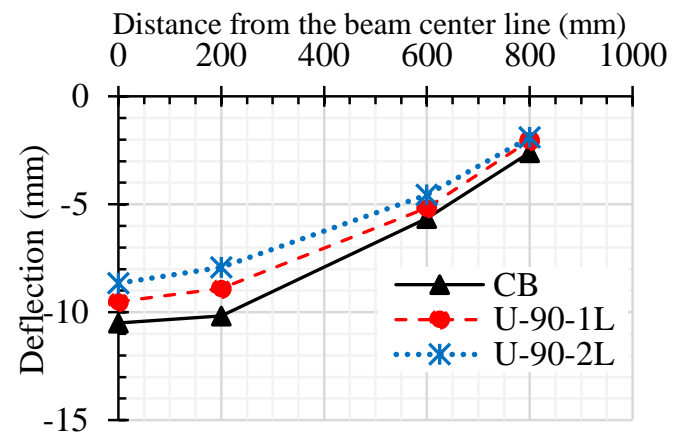

Fig. 8: Deflection profile along the span of CB, U-90-1L and U-90-2L at $290 \mathrm{kN}$

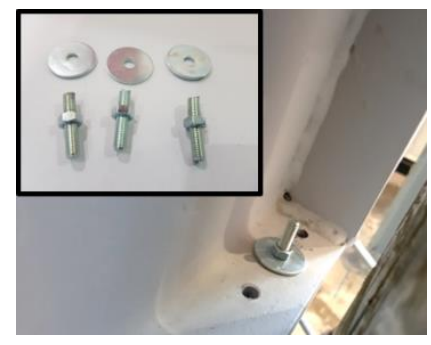

Fig. 9: Shear failure in bolts

\subsection{Effect of Bolt Arrangement}

Utilizing staggered bolt arrangement to fasten a single HFRP strip, with length that is $90 \%$ of the span length, showed higher ultimate capacity than the beam fastened using uniform bolts as shown in Fig. 10 (a). Meanwhile, the use of staggered bolts with shorter HFRP strips revealed similar behavior to that utilizing uniform bolts. Figure 10 (b) presents the load-deflection curves for U-65-1L and ST-65-1L to verify the obtained identical behavior.
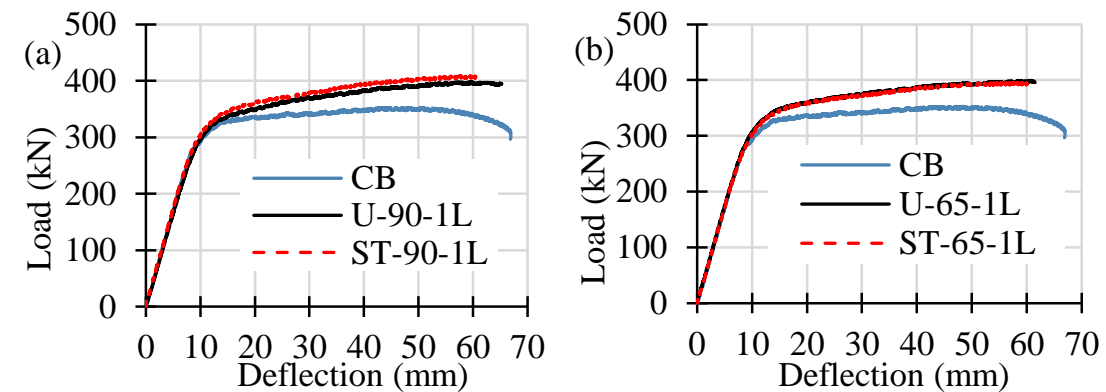

Fig. 10: Effect of bolt arrangement on HFRP strip length: (a) $90 \%$ of the span length and (b) $65 \%$ of the span length.

\subsection{Strain Measurements}

Recorded strain measurements were used to monitor the stress distribution across the beam section and along the HFRP strip. Three-millimeter electrical resistant strain gauges were mounted at two cross-sections of each beam (see Fig. 4) and along half of the HFRP strip as the strain distribution is expected to be symmetrical about the mid-span. A sample strain distribution along the HFRP strip is displayed in Fig. 11 for the strip fastened to beam U-65-1L. In general, the strain profile along the HFRP strip showed higher strains at the mid-span compared to the edge. This behavior can be referred to the deflection of the beam, as the applied loads forced the beam to bend downward causing stretching of 
the strips starting from the mid-span. The stretch then propagated along the HFRP strip. Before yielding, at load of $150 \mathrm{kN}$, the strains were linearly distributed along the strip, however, this linearity was altered at higher loads.

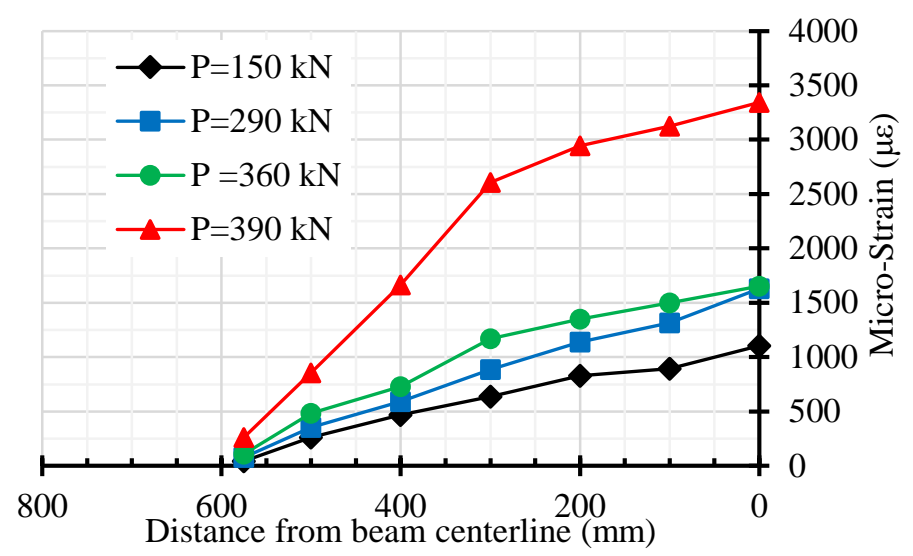

Fig. 11: Strain distribution along half the HFRP strip of U-65-1L

The strain profile for beam U-90-2L and the control beam at $100 \mathrm{~mm}$ away from the beam mid-span, reflecting the segment subjected to pure-moment, is displayed in Fig. 12 (a). The utilization of two HFRP strips significantly reduced the induced stresses at the beam section as shown in Fig. 12 (a). The reduction in the stresses at the beam section reflected the effectiveness of the fastened HFRP strip in resisting the applied loads. The same contribution was observed in the edge segment of the beam, where combined shear and moment stresses were generated, however, the extent of stress reduction through the profile is lower than that presented in the mid-span segment (see Fig. 12 (b)). Comparing the strain profile at the mid-span segment and the edge segment for U-90-2L at $300 \mathrm{kN}$ revealed higher stresses at the mid-span segment, see Fig. $12(\mathrm{c})$.
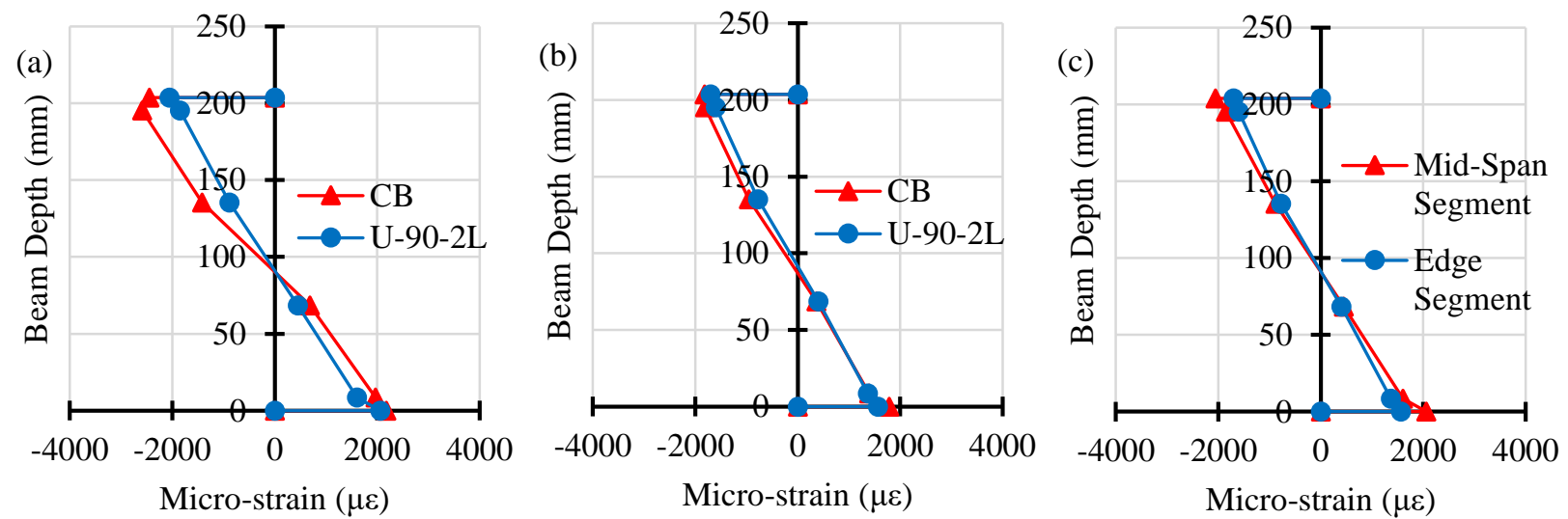

Fig. 12: Strain profile at $300 \mathrm{kN}$ for: (a) CB and U-90-2L at mid-span segment and at (b) edge segment, and (c) strain profile for $\mathrm{U}-90-2 \mathrm{~L}$ at the mid-span segment and the edge segment at $300 \mathrm{kN}$.

\section{Conclusion}

A comprehensive experimental study was conducted to investigate the effectiveness of strengthening steel beams by fastening HFRP strips at the bottom flanges of the beams. The effect of three fastening parameters (HFRP length, HFRP thickness and bolt arrangement) on the performance of the strengthened beams was examined. Increasing the length of the HFRP strips boosted both the yield and ultimate loads of the strengthened beams. Fastening two HFRP strips with lengths of $90 \%$ of the beam clear span revealed $21 \%$ enhancement in the ultimate capacity of the strengthened beam; however, adequate HFRP length should be maintained to avoid shear failure of the bolts. Using staggered bolts instead of uniform bolts to fasten the HFRP strips revealed slight improvement in ultimate capacity of the system. 


\section{Acknowledgements}

The authors would like to acknowledge the financial support provided by the Roadway Transportation and Traffic Safety Research Center (RTTSRC) at UAE University.

\section{References}

[1] C. Batuwitage, S. Fawzia, D. Thambiratnam, and R. Al-Mahaidi, "Evaluation of bond properties of degraded CFRPstrengthened double strap joints," Composite Structures, vol. 173, pp. 144-155, 2017.

[2] Y. Yang, H. Biscaia, C. Chastre, and M. A. Silva, "Bond characteristics of CFRP-to-steel joints," Journal of Constructional Steel Research, vol. 138, pp. 401-419, 2017.

[3] A. El Damatty, and M. Abushagur, "Testing and Modeling of Shear and Peel Behavior for Bonded Steel/FRP Connections," Thin-Walled Structures, vol. 41, pp. 987-1003, 2003.

[4] X. L. Zhao, and L. Zhang, "State-of-the-art review on FRP strengthened steel structures," Engineering Structures, vol. 41, pp. 1808-1823, 2007.

[5] K. Narmashiri, N. R. Sulong, N. R., and M. Z. Jumaat, "Failure analysis and structural behaviour of CFRP strengthened steel I-beams," Construction and building materials, vol. 30, pp. 1-9, 2012.

[6] Y. Yu, S. P. Chiew, and C. K. Lee, "Bond failure of steel beams strengthened with FRP laminates-Part 2: Verification," Composites Part B: Engineering, vol. 42, no 5, pp. 1122-1134, 2011.

[7] J. J. Zeng, W. Y. Gao, and F. Liu, "Interfacial Behaviour and Debonding Failures of Full-Scale CFRP-Strengthened HSection Steel Beams," Composite Structures, vol. 201, pp. 540-552, 2018.

[8] T. W. Siwowski, and P. Siwowska, "Experimental study on CFRP-strengthened steel beams," Composites Part B: Engineering, vol. 149, pp. 12-21, 2018.

[9] S. Jayasuriya, A. Bastani, S. Kenno, T. Bolisetti, and S. Das, "Rehabilitation of Corroded Steel Beams Using BFRP Fabric," Structures, vol. 15, pp. 152-161, 2018.

[10] A. Bastani, S. Das, and S. Kenno, "Rehabilitation of thin walled steel beams using CFRP fabric," Thin-Walled Structures, vol. 143, pp. 106215, 2019.

[11] D. Schnerch, M. Dawood, S. Rizkalla, and E. Sumner, "Proposed design guidelines for strengthening of steel bridges with FRP materials," Construction and building materials, vol. 21, no. 5, pp. 1001-1010, 2007.

[12] M. Heshmati, R. Haghani, and M. Al-Emrani, "Durability of bonded FRP-to-steel joints: Effects of moisture, de-icing salt solution, temperature and FRP type," Composites Part B: Engineering, vol. 119, pp. 153-167, 2017.

[13] N. D. Hai, and H. Mutsuyoshi, "Structural behaviour of double-lap joints of steel splice plates bolted/bonded to pultruded hybrid CFRP/GFRP laminates," Construction and Building Materials, vol. 30, pp. 347-359, 2012.

[14] A. Sweedan, K. El-Sawy and M. Alhadid, "Interfacial behavior of mechanically anchored FRP laminates for strengthening steel beams," Journal of Constructional Steel Research, vol. 80, pp. 332-345, 2013.

[15] A. M. Sweedan, M. M. Alhadid and K. M. El-Sawy, "Experimental study of the flexural response of steel beams strengthened with anchored hybrid composites," Thin-Walled Structures, vol. 99, PP. 1- 11, 2016.

[16] A. E. D. El-Sisi, H. E. D. Sallam, H. A. Salim, and O. M. El-Husseiny, "Structural behaviour of hybrid CFRP/steel bolted staggered joints," Construction and Building Materials, vol. 190, pp. 1192-1207, 2018. 